the Malham Tarn Field Study Centre in excavating a burial site between Gordale Beck and the road to Malham Tarn.

( $T$ o be continued)

${ }^{2}$ Cash, J., "Where There's a Will There's a Way, or Science in the Cottage" (1873).

${ }^{2}$ Rep. Brit. Assoc. 42 (1006)

Mem. Manchester Lit. and Phil. Soc., 52, 11 (1907).

- Rep. Brit. Assoc., 540 (1908).

$\checkmark$ Rep. Brit. Assoc., 432 (1926). - Bates, R. S., "Scientific Societies in the United States" (Massa-
chusetts Institute of Technology, 1945).

'Mem. Manchester Lit. and Phil. Soc., 86, 127 (1943-45).

- Stimson, D., "Scientists and Amateurs"' (Sigma Books, Ltd., 1949).

- Raven, C. E., "English Naturalists from Neckam to Ray : A Study of the Making of the Modern World", pp. 340-2, 354-5 (1947)

${ }^{10}$ Raven, C. E., "Natural Religion and Christian Theology": Vol. 1, "Science and Religion" (1953).

11 Raven, C. E. "Synthetic Philosophy in the Seventeenth Century : a Study of Early Science" (1945).

12 Taylor, F. Sherwood, "The Teaching of the Physical Sciences at the End of the Eighteenth Century", Phil. Mag., 150th Comm. No. 144. Cf. also Babbage, C., "Reflections on the Decline of on the dependence of scientiflc work on the amateur.

12 Rep. on the Universities and Industry Conference, 1952, p. 7 (Federation of British Industries, 1953).

14 Lack, D., "Birds and the Field Centres", C.P.F.S. Ann. Rep., 24 $(1949-50)$

15 "Co-operation in Biological Studies", Discovery, 11, 328 (1950).

16 J. Animal Ecol., 15, 82 (1946).

$17 \mathrm{~J}$. Animal Ecol., 15, 130 (1946); 17, 151 (1947) ; 18, 187 (1949).

${ }^{18}$ Beveridge, W. I. B., "The Art of Scientiflc Investigation", 337 (W. Heinemann, Litd., London, 1950).

19 Advancement of Science, 8, 49 (1951).

${ }^{20}$ Times Educ. Suppl., 89 (1953).

s1 Times Educ. Suppl., 686, 820 (1953).

${ }_{22}$ Times Educ. Suppl., 766, 825 (1953).

\section{MINERAL DRESSING AT THE ROYAL SCHOOL OF MINES, LONDON}

$\mathrm{W}$

ITHIN recent decades the increasing industrial demand for engineering metals and nonmetallic minerals has led to the exploitation of mineral deposits too low in grade or too complex in ore structure to be profitably worked by the simpler methods in use thirty years ago. Though the demand still rises steadily, most of the older deposits are already in full production or even approaching exhaustion. Difficulties of climate, power, access and mechanized mining have been overcome to a gratifying extent; but the extraction of small quantities of valuable material from a large amount of associated host-rock still presents many difficulties.

In addition to modernized developments of the older methods of mineral dressing, in which gravity, ferromagnetism, electrical conductivity and the skill of the hydro-metallurgist are exercised, the process of froth-flotation has grown in importance. It provides the only method of concentration in many ore-dressing plants, and is used at some point in most of the others. The process is applied to finely ground ore pulped with water. Each ore particle must be so small that its settling velocity is of the Stokesian rather than the Newtonian order. There are two main reasons for this : first, the separation of value from waste depends on differences between the surface tensions of the particles undergoing treatment, and these differences cannot be exploited if the masses of the reacting particles introduce a high gravitational pull; secondly, the desired particles must be freed by grinding from those which are to be rejected, and this liberation is only effective when a substantial part of the ore has been ground well below $50 \mu$. Particles only a few microns in diameter are usually responsive to treatment.

Liberation by wet grinding is practised under close physical control. The prepared ore-pulp next receives small additions of chemicals which control flocculation, detergency and the surface characteristics of the various minerals in aqueous suspension. The $p H$ must be held within defined limits during the whole of the treatment. A copious supply of air-bells is next blown through the pulp. As a result, particles which are relatively aerophilic are attracted into the interface between water and air and rise to the surface of the pulp where, with the help of a suitable frothing chemical, they form an unstable mineralized froth which is removed from the system. Huge tonnages of ore are treated daily along these lines.

In recognition of the vital importance to industry of a trained scientific outlook in developing and operating such processes as the one outlined above, the University of London instituted a degree course in mineral dressing in 1952. This is a B.Sc. option (engineering) in metallurgy, and it carries with it the associateship of the Royal School of Mines. On March 17 the new laboratories built in connexion with this degree course and its associated research

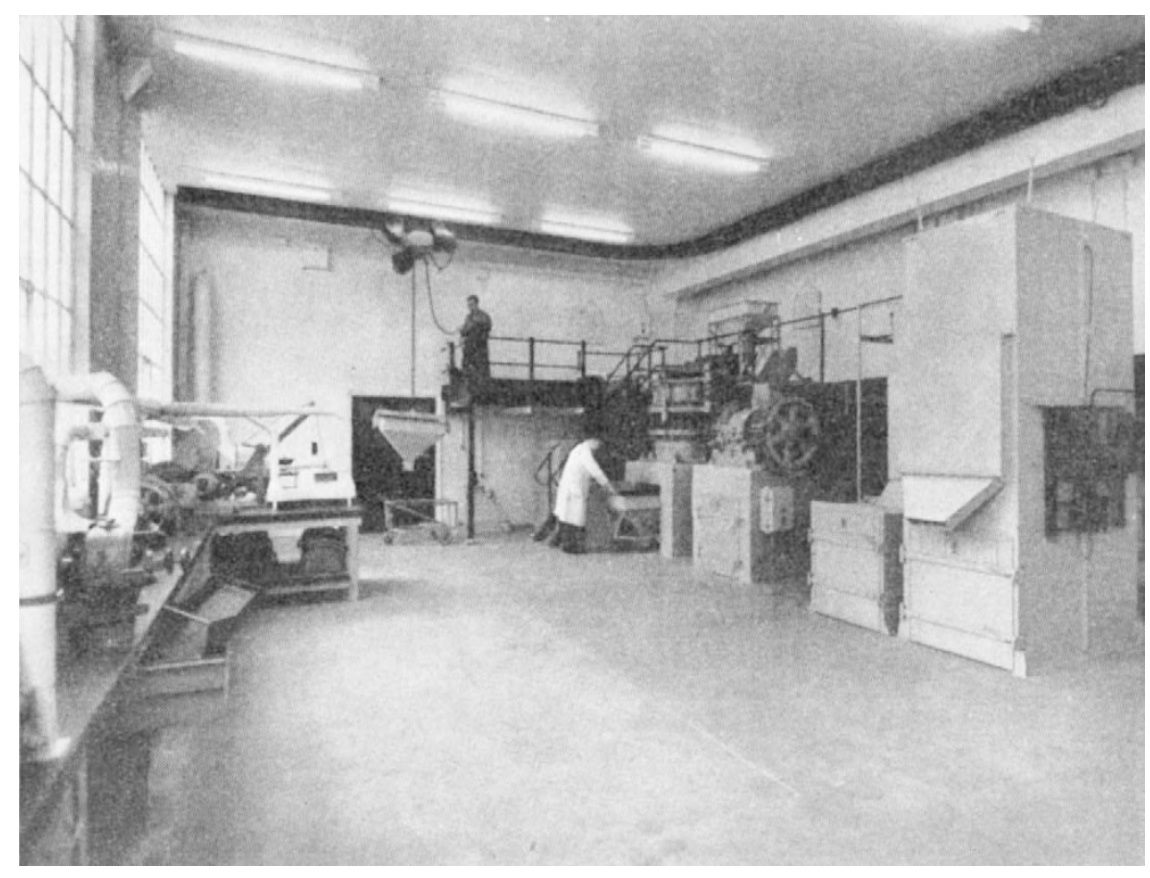

Fig. 1. Crushing room. Right, jaw crusher, Symons cone crusher, set of rolls, automatic sample splitter and a Sherwen screen; left, small crushing machines. Ore is moved by electric crane and mono-rail 


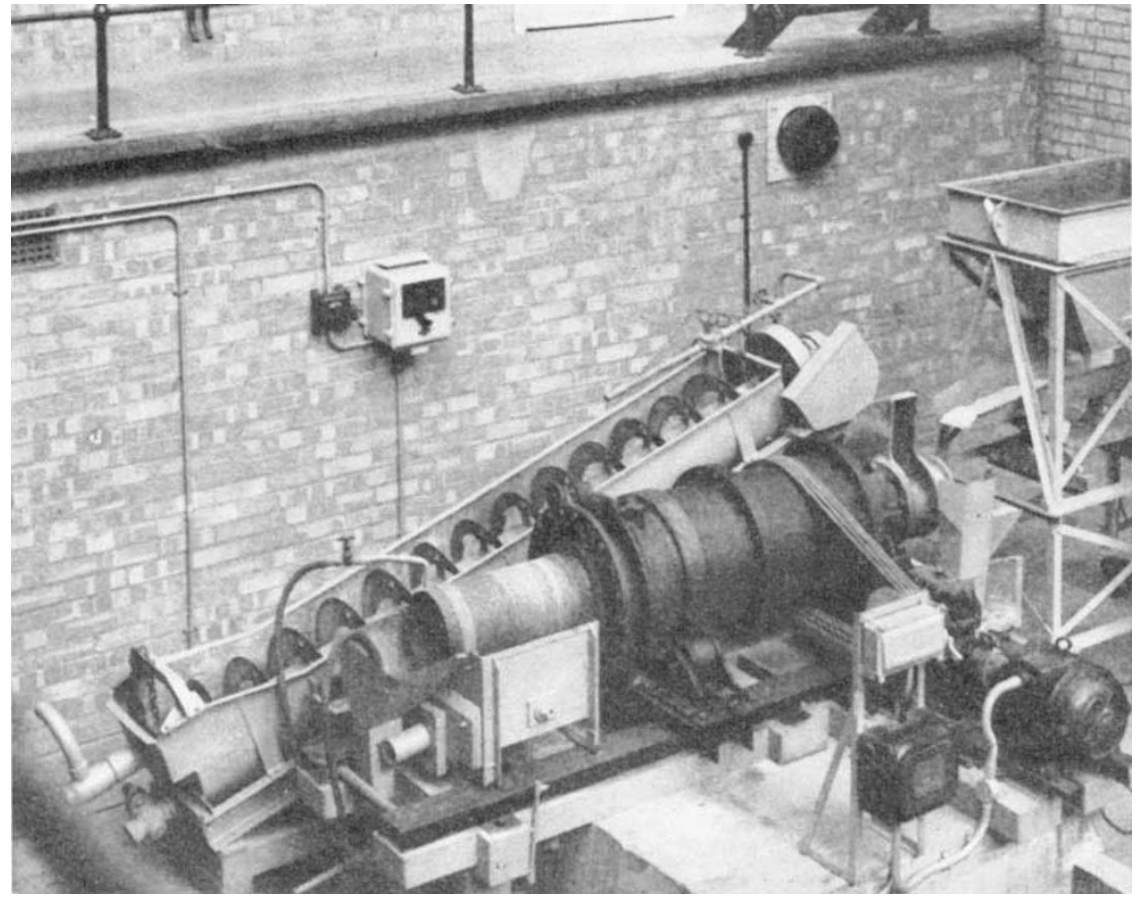

Fig. 2. Small wet-grinding mill in closed circuit with an Atkins classifier microscope ; and a com. paratively new method of testing the surface condition of small particles. Although the operations shown were limited by considerations of suitability for rapid demonstration as well as by the fact that the research work is only now settling down in its now home, it is clear that a wide field of scientific investigation has yet to be surveyed in terms of the special requirements of the mineral industry, and that measures have been taken to correlate this work with its commercial utilization. In this connexion, the traditional policy of making suitable provision for industrial ore-testing at the Royal School of Mines has been retained, so far as considerations of space and staffing permit.

One overriding justification for the new degree course and its allied activities is the shortage of suitably trained mineraldressing engineers. This dearth has proved a restrictive factor in the development of the large low-grade deposits on which modern industry increasingly depends, and is felt in every part of the world. During the next few years the Mineral Dressing Section of the Royal School of Mines expects to meet part of this need by giving accelerated trajning to postgraduate students ; but it is felt that the long-term answer involves a steady increase in the number of graduates specially trained in this subject. Since much of the work can be done in the mill laboratory under pleasant, interesting and clean conditions it is not proposed to restrict intake to men only, though all those entering must be prepared to spend the first few years of their working careers outside Great Britain.

E. J. Pryor

\section{OBITUARIES}

\section{Lady Robinson}

The death of Gertrude Maud Robinson, wife of Sir Robert Robinson, Waynflete professor of organic chemistry in the University of Oxford, came as a profound shook to chemists throughout the world, and in particular to those in many universities who have been privileged to know her. Her contributions to chemical knowledge have been substantial in spite of many pressing calls on her time and energy. With characteristic enthusiasm she was working in the laboratory a few days before her death, and it is in the dual role of an indefatigable research worker and a kindly hostess that she will long be remembered. In particular, the younger members of the teaching staffs and their wives have reason to be profoundly grateful to her ; she found time to take personal interest in them and their families, which lasted long after they moved elsewhere. One other aspect of her 